\title{
Profile of patients seen at Pietersburg and Mankweng breast cancer clinics in Limpopo
}

\author{
R Mavhungu, ${ }^{1}$ BSc (Med Sci); M M Z U Bhuiyan, ${ }^{1}$ DTH, FRCS (Glasgow), MMed; F Ooko, ${ }^{2}$ FC Rad Onc (SA), M Phil, PG Dip Pall Med \\ ${ }^{1}$ Department of General Surgery, Pietersburg and Mankweng hospitals, University of Limpopo, Polokwane, South Africa \\ ${ }^{2}$ Department of Radiation Oncology, Pietersburg and Mankweng hospitals, University of Limpopo, Polokwane, South Africa
}

Corresponding author: M M Z U Bhuiyan (bhuiyanmirza@gmail.com)

Background. Breast cancer is the most common cancer diagnosed among women worldwide. It is the most prevalent cancer and leading cause of death among South African (SA) women. The increasing incidence of breast cancer is a major health concern. Until now, the distribution of breast cancer demography, stage at first presentation, and histological characterisation have not been studied in Limpopo Province, SA.

Objectives. To record the demographic profile of breast cancer patients, to report the stage at the time of presentation and to characterise the pattern of malignant disease in Limpopo, SA.

Methods. We conducted a retrospective descriptive review of the records of patients managed at Pietersburg Hospital oncology and Mankweng Hospital breast cancer clinics during the period 1 March 2015 - 28 February 2017. Stata was used to analyse data.

Results. A total of 248 patients with a mean age of 55 years were included for analysis, 7 males (3\%) and 241 females (97\%). Capricorn and Vhembe districts constituted $32 \%$ and $27 \%$ respectively. The majority $(69 \%)$ of patients were diagnosed with disease stage III or IV. The most common histological type was invasive ductal cell carcinoma (IDC) (87\%).

Conclusions. More than one-third of patients were younger than 50 years. The majority (69\%) had an advanced breast cancer (stage III or IV). We recommend provision of mammography services in regional hospitals.

S Afr Med J 2021;111(11b):1129-1131. https://doi.org/10.7196/SAMJ.2021.v111i11b.16108

Breast cancer is the most prevalent cancer and leading cause of death among women worldwide. ${ }^{[1]}$ The average lifetime risk of breast cancer for a woman in the USA has been estimated at $12.3 \%$ with about 41400 deaths reported in 2018. ${ }^{[1]}$ The global incidence increased from 1.7 million in 2005 to 2.4 million cases in $2015^{[2]}$ and in Africa is predicted to double by $2050 .{ }^{[3]}$ Incidence rates are lower in low- and middle-income countries (LMICs) than in high-income countries; however, the rates are increasing very rapidly in LMICs owing to adoption of a western lifestyle, including such habits as shorter breastfeeding time, use of postmenopausal hormonal therapy, late age at first term pregnancy or lower parity. Another risk factor of breast cancer is physical inactivity, leading to obesity. ${ }^{[4]}$ The incidence in subSaharan Africa was estimated to be 22.4 per 100000 cases in 2018. ${ }^{[5]}$ Breast cancer mortality rates in LMICs remain high as a result of late presentations and inadequate access to good healthcare. ${ }^{[6]}$

Breast cancer, along with cervical cancer, has been identified as a priority for the national healthcare services in South Africa (SA) ${ }^{[7]}$ The SA National Cancer Registry reported breast cancer in 2014 as a leading cause of cancer deaths among women. ${ }^{[8]}$ A 5-year mortality rate of 47\% was recorded for SA women. ${ }^{[9]}$ Breast cancer as a social problem has become an urgent challenge in LMICs. It is increasing dramatically, with 19.7 million cases projected to occur in the next decades. ${ }^{[10,11]}$

This present study is the first to report the demographic profile, stage at presentation, and the characteristics of breast cancer patients in Limpopo Province, SA. Before March 2015, breast cancer patients were managed by surgeons in the general surgery department, together with patients admitted for other surgical conditions. Breast cancer patients would wait $3-6$ months for operations. In March 2015, a multidisciplinary clinic for the care of breast cancer patients was established at Mankweng Hospital. This hospital is a tertiary teaching institution of the University of Limpopo located $30 \mathrm{~km}$ east of Polokwane, the provincial capital.

The clinic at Mankweng is the only such facility in Limpopo serving the population of 5.98 million people. ${ }^{[12]}$ The clinic operates once a week, staffed with adequate personnel, but does not have its own oncology and radiation facilities; for these services, the clinic is dependent on the radiation department at Pietersburg Hospital $30 \mathrm{~km}$ away.

The main objective of this study was to record the demographic features of attending patients, stage at presentation and histological patterns of malignancy identified in breast cancer patients treated at Mankweng. We anticipate that the information obtained from this study will guide the authorities responsible for provincial policy on breast cancer prevention, treatment and resource allocation programmes.

\section{Methods}

We conducted a retrospective, descriptive, cross-sectional record review of patients managed at Mankweng breast cancer clinic during the period March 2015 - February 2017. Files with full correct data of all patients diagnosed with breast cancer were included in the study; incomplete records were excluded. The primary inclusion criterion was histological confirmation of breast cancer. A password-protected data bank in Excel (Microsoft 2013, USA) was created to record information on breast cancer patients. The clinic registers were used as a starting point for data collection. Patients' files were retrieved from the hospital archive to compile the data bank. The analysed variables were age, gender, home district of patient, stage of the disease and histological type of malignant tumours.

The statistical software package Stata (Stata Corp., USA) was used for data analysis. Continuous variables were expressed as means and standard deviations (SDs). Patients were allocated by age to one of 
five categories. Stages at presentation were grouped into early (stages I and II) and late (stages III and IV). The categorical variables were described as proportions and frequency tables. Ethical approval was obtained from the Pietersburg-Mankweng Research Ethics Committee (ref. no. PMREC-01UL2017).

\section{Results}

A total of 291 patients' files formed the primary database for this study. Forty-three patients' records were removed from the list because of incomplete information; therefore 248 patients' records were finally included for analysis. Table 1 shows data of the breast cancer patients during the 2-year study period. The mean age was 55 years. Women younger than 50 years of age comprised $38 \%$ of the total (Table 1); $8 \%$ were younger than 35 years. Females comprised $97 \%$ of all cases. The majority of patients admitted to the clinic came from the Capricorn district. Most of them were at an advanced stage III or IV ( $n=170 ; 69 \%)$; patients with

\begin{tabular}{|c|c|}
\hline Variables & $n(\%)^{*}$ \\
\hline Mean age (years) & 55 \\
\hline \multicolumn{2}{|l|}{ Gender } \\
\hline Males & $7(3)$ \\
\hline Females & $241(97)$ \\
\hline \multicolumn{2}{|l|}{ Age (years) } \\
\hline $20-34$ & $21(8)$ \\
\hline $35-49$ & $75(30)$ \\
\hline $50-64$ & $84(34)$ \\
\hline $65-79$ & $55(22)$ \\
\hline$>79$ & $14(6)$ \\
\hline \multicolumn{2}{|l|}{ Home district } \\
\hline Capricorn & $80(32)$ \\
\hline Vhembe & $68(27)$ \\
\hline Mopani & $39(16)$ \\
\hline Waterberg & $34(14)$ \\
\hline Sekhukhune & $26(11)$ \\
\hline \multicolumn{2}{|l|}{ Stage at first presentation } \\
\hline I \& II & $78(31)$ \\
\hline III \& IV & $170(69)$ \\
\hline \multicolumn{2}{|l|}{ Histological type } \\
\hline Ductal cell carcinoma & $217(87)$ \\
\hline Colloid carcinoma & $9(4)$ \\
\hline Mucinous carcinoma & $4(2)$ \\
\hline Papillary carcinoma & $4(2)$ \\
\hline Lobular carcinoma & $2(1)$ \\
\hline Ductal carcinoma in situ & $7(3)$ \\
\hline Lobular carcinoma in situ & $1(<1)$ \\
\hline Medullary carcinoma & $1(<1)$ \\
\hline $\begin{array}{l}\text { Mixed ductal and lobular } \\
\text { carcinoma }\end{array}$ & $3(1)$ \\
\hline
\end{tabular}

stages I and II comprised only $31 \%$ of total admissions. We found that women aged 50 - 64 years were in much more advanced stages as compared with the other age groups (Fig. 1). The majority of patients (87\%) presented with invasive ductal cell carcinoma (IDC). Colloid carcinoma was present in 3.6\% and ductal carcinoma in situ (DCIS) in $3 \%$, together constituting nearly $7 \%$. Mucinous carcinoma was present in $2 \%$, papillary in $2 \%$, medullary in $<1 \%$, lobular carcinoma in situ (LCIS) in $<1 \%$, and mixed ductal and lobular carcinoma was found in a relatively small number ( $n=3$; Table 1$)$.

\section{Discussion}

The main objective of this study was to report patients' demographic profiles, stages of disease at first presentation, and characterise the histological type of breast cancer for all patients included in this research at Mankweng Hospital, a tertiary hospital in Limpopo.

Of the nine provinces of SA, Limpopo is the fifth largest, and covers $125754 \mathrm{~km}^{2}{ }^{\left[{ }^{[12]}\right.}$ The population is $\sim 5.98$ million, and Limpopo Province is administratively divided into five districts: Capricorn, Vhembe, Mopani, Sekhukhune and Waterberg. Each district has a regional hospital: Tshilidzini, Letaba, St. Rita's, Philadelphia, and Mokopane hospitals. Pietersburg and Mankweng are the tertiary hospitals in the province, situated in Capricorn district. All patients diagnosed with breast cancer in the public sector, with a confirmed histological diagnosis, attend the breast oncology clinic. Mammography services are only available at Pietersburg and Mankweng hospitals, dealing with all patients from the whole province, which results in long waiting lists for mammography investigations.
We found that $32 \%$ of the patients came from Capricorn district. There are various possible reasons for this; for example, it could be a true reflection since all breast cancer patients around Mankweng are referred directly to the clinic. Another explanation is that breast cancer patients from other districts seek alternative help because of complex pathways to access the clinic.

The mean (SD) age of breast cancer patients at the time of diagnosis was 55 (14.4) years. This is similar to other studies conducted in SA. In a study conducted at Chris Hani Baragwanath Academic Hospital, Johannesburg, results of mean (SD) age were similar: 54.4 (14.2). ${ }^{[13]} \mathrm{A}$ study conducted to understand the pathway of breast cancer diagnosis among women in Cape Town found the mean age to be 52 years. ${ }^{[14]}$ In our series, $38 \%$ of patients were below the age of 50 years. Some studies from Africa also report mean age below 50 years. ${ }^{[15]}$ The study by Azubuik et al.$^{[16]}$ recorded that breast cancer in Africa tends to occur in relatively younger age groups and among premenopausal women compared with the western population.

To date, there has been no evidence related to high risk of breast cancer in the HIV-positive population. However, strong evidence suggesting younger age at diagnosis for the HIV-positive population as compared with the HIV-negative population has been presented. An SA report by Van Zyl et al. ${ }^{[17]}$ found the mean (SD) age at presentation of breast cancer in the HIV-positive group to be $\sim 10$ years younger (44.86 (9) years), compared with the entire population (54.56 (13.62) years) and the HIV-negative group (53.18 (12.48) years). Another study, by Kohler et al., ${ }^{[18]}$ reported that in Malawi, 55\% of cases occurred in women below the age of 50 years. We do not know why many patients

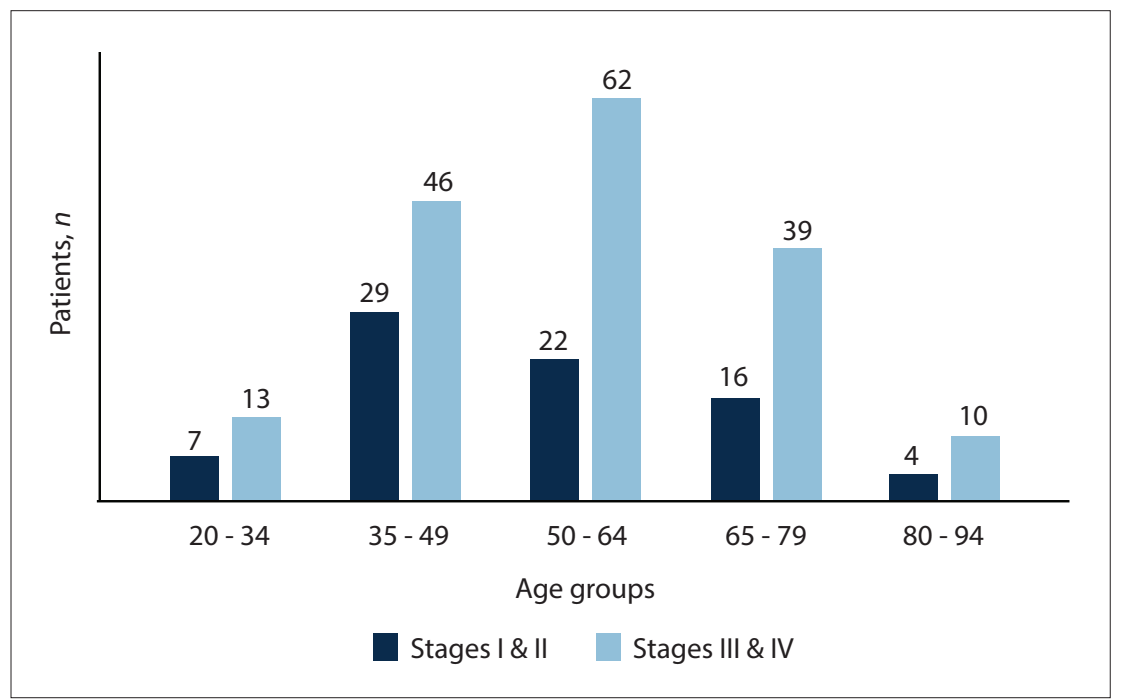

Fig. 1. Distribution of patients by breast cancer stage and age. 
in our study are young. Globally, breast cancer occurrence in young patients ( $<40$ years) constitutes $7 \%$ of all diagnosed breast cancer. ${ }^{[19]}$

Nearly $70 \%$ of the patients in our study were diagnosed with already advanced cancers. However, the 50 - 64-year-old age group presented much later as compared with other groups. In this subgroup, $83 \%$ of patients came markedly late. Advanced stage at presentation has been reported in an LMIC, Kenya, with as many as $89 \%$ of patients with a late stage of cancer. ${ }^{[20]}$ In an urban SA clinic in Johannesburg, two-thirds of patients presented with locally advanced breast cancers. ${ }^{[21]}$

Early diagnosis has a profound implication for prognosis, survival and personal or social costs; therefore early detection of breast cancer should be prioritised. ${ }^{[22]}$ Primary healthcare services have an important role to play in breast care education, and promotion of cancer symptoms awareness. In Limpopo, there are no mammography facilities in any regional hospitals. Consequently, patients have to travel up to $300 \mathrm{~km}$ to Pietersburg or Mankweng for mammograms. This is expensive for patients, makes waiting lists much longer, and establishing the final diagnosis is significantly delayed. Many of these patients present too late to health service facilities, contributing to higher mortality, morbidity and also to considerably high costs. Regional hospitals in Limpopo should be equipped with wellfunctioning mammography facilities which are essential in early diagnosis of breast cancer. In addition, they should be staffed with personnel trained on breast cancer care.

Most of the women in our study had IDC (87\%). A similar trend was found in Malawi where IDC was the most common histological type (86\%). ${ }^{[18]}$ Nearly $80 \%$ of patients required mastectomy.

The best treatment for advanced breast cancer is surgery, chemotherapy and radiotherapy. In addition, endocrine therapy and monoclonal antibody trastuzumab is required according to hormonal and HER 2-receptor status. The surgical treatment is often the only modality available in most low-resource settings where modified radical mastectomies are the most commonly performed operations.

\section{Conclusion}

In conclusion, this study has defined the breast cancer population in the newly established breast cancer clinic in the rural province of Limpopo, northern SA. More than one-third of our participants were younger than 50 years and nearly $10 \%$ were younger than 35 years (8\%). Most of them came from Vhembe and Capricorn districts. Advanced stage at presentation is still a challenge in this institution.

A further investigation to determine the factors contributing to advanced stage at presentation would provide information on the causes and reasons for such undesirable delays in the health service system. Information obtained from this study may help in guiding the establishment of prevention strategies. Mammography machines should be made available in regional hospitals.

\section{Declaration. None.}

Acknowledgements. We acknowledge and thank the breast cancer clinic staff, medical and radiation oncology staff, as well as the record management staff, at Mankweng and Pietersburg hospitals for their tireless support with records retrieval.

Author contributions. Equal contributions.

Funding. None.

Conflicts of interest. None.

1. Bevers TB, Helvie M, Bonaccio E, et al. Breast cancer screening and diagnosis, version 3.2018, NCCN clinical practice guidelines in oncology. J Natl Compr Canc Netw 2018;16 (11):1362-1389. https://doi. org/10.6004/jnccn.2018.0083

2. Fitzmaurice C, Allen C, Barber RM, et al. Global, regional, and national cancer incidence, mortality, years of life lost, years lived with disability, and disability-adjusted life-years for 32 cancer groups, 1990 to 2015 A systematic analysis for the Global Burden of Disease study. JAMA Oncol 2017;3(4):524-548. https://doi. org/10:1001/jamaoncol.2016.5688

3. Chokunonga E, Borok MZ, Chirenje ZM, Nyakabau AM, Parkin DM. Trends in the incidence of cance in the black population of Harare, Zimbabwe 1991-2010. Int J Cancer 2013;133:721-729. https://doi. org/10.1002/ijc.28063

4. Corbex M, Bouzbid S, Boffetta P. Features of breast cancer in developing countries, examples from NorthAfrica. Eur J Cancer 2014;50(10):1808-1818. https://doi.org/10:1016/j.ejca.2014.03.016

5. Adeloye D, Sowunmi, OY, Jacobs W, et al. Estimating the incidence of breast cancer in Africa: A systematic review and meta-analysis. J Glob Health 2018;8(1):1-18. https://doi.org/10.7189/jogh.08.010419

6. Yip CH, Buccimazza I, Hartman M, Deo SV, Cheung PS. Improving outcomes in breast cancer for low- and middle-income countries. World J Surg 2015;39(3):686-692. https://doi.org/10.1007/s00268-014-2859-6

National Department of Health, South Africa. Breast Cancer Prevention and Control Policy. 2017. http:// www.health.gov.za/index.php/shortcodes/2015-03-29-10-42-47/2015-04-30-08-18-10/2015-04-30-0824-27 (accessed 21 September 2019).

8. South African National Cancer Registry. Summary statistics of cancer diagnosed histologically in 2014 . 2014. https://www.cansa.org.za/south-african-cancer-statistics/ (accessed 24 April 2019).

9. Allemani C, Weir HK, Carreira H, et al. Global surveillance of cancer survival 1995 - 2009: Analysis of individual data for 25676887 patients from 279 population-based registries in 67 countries (CONCORD-2). Lancet 2015;385(9972):977-1010. https://doi.org/10.1016/S0140-6736(14)62038-9

10. Ginsburg OA, Rositch F, Conteh L, Mutebi M, Paskett ED, Subramanian S. Breast cancer disparities among women in low- and middle-income countries. Curr Breast Cancer Rep 2018;10(3):179-186. https://doi org/10.1007/s12609-018-0286-7

1. Anderson BO. Breast cancer - thinking globally. Science 2014;343(6178):1403. https://doi.org/10.1126 science. 1253344

2. Statistics South Africa. Midyear population estimates 2019. http://www.statssa.gov.za/?p=7988 (accessed

13. Cubasch H, Dickens C, Joffe M, et al. Breast cancer survival in Soweto, Johannesburg, South Africa. A
13. receptor-defined cohort of women diagnosed from 2009-2011. Cancer Epidemiol 2018;52:120-127. https://doi.org/10.1016/j.canep.2017.12.007

14. Moodley J, Cairncross L, Naiker T, Momberg M. Understanding pathways to breast cancer diagnosis among women in the Western Cape Province, South Africa: A qualitative study. BMJ Open 2016;6:e00905. https://doi.org/10.1136/bmjopen-2015-009905

15. Abdulrahman GO, Rahman GA. Epidemiology of breast cancer in Europe and Africa. J Cancer Epidemio 2012:1-5. https://doi.org/10.1155/2012/915610

16. Azubuik SO, Muirhead C, Hayes L, McNally R. Rising global burden of breast cancer: The case of subSaharan Africa (with emphasis on Nigeria) and implications for regional development: A review. World Surg Oncol 2018;16:63. https://doi.org/10.1186/s12957-018-1345-2

17. Van Zyl N, Minné C, Mokone DH. Human immunodeficiency virus infection in breast cancer patients: The prevalence thereof and its effect on breast cancer characteristics at Dr George Mukhari Academic Hospital breast clinic, Ga-Rankuwa, South Africa. S Afr J Radiol 2018;22(2):a1361. https://doi org/10.4102/saj.v22i2.1361

18. Kohler RE, Moses A, Krysiak R, Liomba NG, Gopal S. Pathologically confirmed breast cancer in Malawi: A descriptive study: Clinical profile of breast cancer. Malawi Med J 2015;27(1):10-12. http://doi. org/10.4314/mmj.v27i1.3

19. Gewefel H, Salhia B. Breast cancer in the adolescent and young adult women. Clin Breast Cancer 2014;14(6):390-395: https://doi.org/10.1016/j.clbc.2014.06.002

20. Othienyo-Abinya NA, Nyabola LO, Abwao HO, Ndenge P. Postsurgical management of patients with breast cancer at Kenyata National Hospital. East Afr Med J 2002;79(3):156-162. https://doi.org/10.4314/ breast cancer at Keny
eamj.v79i3.8897

21. Rayne S, Schnippe K, Kruger D, Benn C-A, Firnhaber C. S Afr Med J 2019;109(3):159-163. Delay to diagnosis and breast cancer stage in an urban South African breast clinic. https://doi.org/10.7196/ diagnosis and breast can
SAMJ.2019.v109i3.13283

22. Daroudi R, Akbari Sari A, Nahvijou A, Kalaghchi B, Najafi M, Zendehdel K. The economic burden of breast cancer in Iran. Iran J Public Health 2015;44(9):1225-1233.

Accepted 5 September 2021 